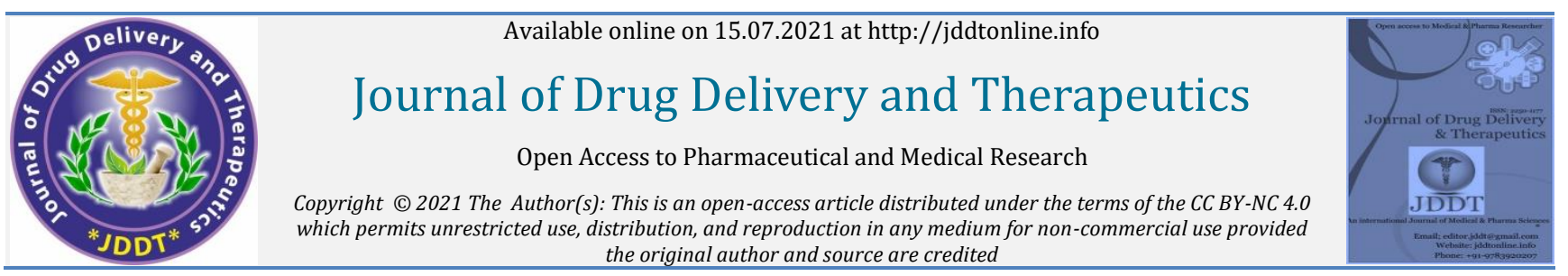

Open Access Full Text Article the original author and source are credited

\title{
Formulation and Evaluation of Self Nano Emulsifying Drug Delivery System of Raloxifene Hydrochloride
}

\author{
T. Gayathri*1, M. Venkata Ramana², N. Rama Rao ${ }^{3}$ \\ Department of pharmaceutics, Chalapathi Institute of Pharmaceutical Sciences (Autonomous), Lam, Guntur, Andhra Pradesh-522034, India
}

Article Info:

Article History:
Received 08 May 2021
Accepted 24 June 2021
Available online 15 July 2021

*Address for Correspondence:

T. Gayathri, Department of pharmaceutics, Chalapathi Institute of Pharmaceutical Sciences (Autonomous), Lam, Guntur, Andhra Pradesh-522034, India.

\section{Abstract}

Raloxifene hydrochloride (RLX) is a selective Estrogen-receptor modulator used to treat osteoporosis as well as breast and endometrial cancer prevention. The bioavailability of RLX is only $2 \%$ due to substantial pre-systemic clearance. The goal of this research was to customise and characterise RLX-loaded self-nanoemulsifying drug-delivery systems (SNEDDS) by using bioactive excipients that impact drug metabolism. The droplet size, zeta potential and drug content determination of optimized formulation (F-06) was found to be $147.5 \mathrm{~nm},-28.8,99.67 \%$ respectively. The drug release study from the nano formulation was studied in Phosphate buffer 6.8 for all the formulations F1,F2,F3,F4,F5,F6 and F7. The optimized formulation was found to be F6

Keywords: Raloxifene hydrochloride, nanoemulsion, SNEDDS etc.,

Cite this article as:

Gayathri T, Venkata Ramana M, Rama Rao N, Formulation and Evaluation of Self Nano Emulsifying Drug Delivery System of Raloxifene Hydrochloride, Journal of Drug Delivery and Therapeutics. 2021; 11(4):16-19 DOI:http://dx.doi.org/10.22270/jddt.v11i4.4857

\section{INTRODUCTION:}

The quick identification of numerous highly potent novel chemical entities has resulted from the advent of combinatorial chemistry and high throughput screening. However, there has been a growing trend toward the identification of lead compounds with good therapeutic importance that fail to elicit their maximum therapeutic effects due to poor aqueous solubility. While these qualities work together to offer optimal drug-receptor binding properties, they also lead to poor drug solubility and membrane permeability. Many of these medications have poor and variable bioavailability since solubility and permeability are regarded criteria for oral absorption. The high dose-to-solubility ratio of such medications can be identified, and food coadministration typically increases bioavailability. ${ }^{1}$

Raloxifene hydrochloride (RLX) is a selective Estrogenreceptor modulator used to treat osteoporosis as well as breast and endometrial cancer prevention. The bioavailability of RLX is only $2 \%$ due to substantial presystemic clearance. The goal of this research was to customise and characterise RLX-loaded self-nanoemulsifying drug-delivery systems (SNEDDS) by using bioactive excipients that impact drug metabolism. ${ }^{2}$

\section{MATERIALS AND METHODS:}

\section{Materials:}

Raloxifene Hydrochloride was a generous gift from Delexcel Pharma Pvt. Ltd., Olive oil from Loba chemie Pvt. Ltd., Mumbai, India. Isopropyl myristate (IPM), Oleic acid Himedia
Laboratories Pvt. Ltd., Tween 20, Tween 40, Tween 60, Tween 80 from Himedia Laboratories Pvt. Ltd., Mumbai, India. Propylene glycol Qualigen Fine Chemical, Mumbai. PEG 400 from SD Fine Chemicals Pvt. Ltd., Mumbai

\section{Method:}

\section{Formulation of SNEDDS}

\section{Selection of SNEDDS Components Oil (solubility studies)}

The shake flask method was used to determine the solubility of Raloxifene Hydrochloride in various buffers, oils, surfactants, and co-surfactants. The combination was maintained in sealed vials with an excess amount of medication added to $2 \mathrm{~mL}$ of each excipient. A vortex mixer (Remi, Mumbai, India) was used to facilitate the solubilization. Sealed vials were stirred in a water bath Figure 1: at $40^{\circ} \mathrm{C}$ for $24 \mathrm{~h}$ and allowed to reach equilibrium at $30^{\circ} \mathrm{C}$ for $72 \mathrm{~h}$. Each vial was centrifuged at $15,000 \mathrm{rpm}$ for 10 min using a centrifuge (Remi) followed by removal of the undissolved drug by filtering with a membrane filter $(0.45$ $\mu \mathrm{m})$. Samples were suitably diluted with methanol and drug concentration was obtained via a validated UV method at $244 \mathrm{~nm}$ using methanol as a blank, using a double-beam UV visible spectrophotometer (Shimadzu 1700, Shimadzu, Tokyo, Japan). The experiment was repeated in triplicate and the results represent the mean value $(\mathrm{mg} / \mathrm{mL} \pm \mathrm{SD}){ }^{3}$

\section{Preparation of SNEDDS formulations}

On the basis of the "Solubility studies" section, the oil (Olive oil), surfactants (Tween 20, Tween 40, Tween 60, Tween 80), and cosurfactants (PEG 400) were selected due to their 
greater solubility enhancement effect on Raloxifene Hydrochloride. Various formulations were tried as shown in following Table. The formulations were prepared by dissolving Raloxifene Hydrochloride $(8.04 \% \mathrm{w} / \mathrm{w})$ in the mixture of oil, surfactant, and cosurfactant and were heated at $50^{\circ} \mathrm{C}$ in an isothermal water bath. This mixture was mixed well and subjected to vortexing using cyclomixer (Remi, India), until a transparent preparation was obtained. All the mixtures were stored at ambient temperature for further use. 1

Table 1: formulations of SNEDDS

\begin{tabular}{|l|l|l|l|l|l|l|l|}
\hline Ingredients & F1 & F2 & F3 & F4 & F5 & F6 & F7 \\
\hline Raloxifene Hydrochloride & $5 \%$ & $5 \%$ & $5 \%$ & $5 \%$ & $5 \%$ & $5 \%$ & $5 \%$ \\
\hline Olive oil & 20 & 20 & 30 & 30 & 40 & 50 & 50 \\
\hline Tween 80 & 54.5 & 69.6 & 61 & 52 & 35 & 46 & 44 \\
\hline PEG 400 & 25.5 & 10.4 & 9 & 18 & 25 & 4 & 6 \\
\hline
\end{tabular}

\section{Percent transmittance:}

The sample was made by vortexing $0.1 \mathrm{~mL}$ of SNEDDS with 5 $\mathrm{mL}$ distilled water for 30 seconds. The $\%$ transmittance at $650 \mathrm{~nm}$ was measured using a UV spectrophotometer.

\section{Self-emulsification and precipitation assessment}

In a brief, different compositions were classified based on the clarity and apparent stability of the resulting emulsion. Dropwise addition of the preconcentrate (SNEDDS) into 250 $\mathrm{mL}$ of distilled water in a glass beaker at room temperature was used for visual assessment. The ingredients were gently mixed with a glass rod or a magnetic stirrer at a speed of 100 rpm. They were observed immediately after dilution for assessment for self-nano emulsification efficiency, appearance (transparency), phase separation, and precipitation of drug. Precipitation was evaluated by visual inspection of the resultant nanoemulsion after $24 \mathrm{~h}$. The formulation were then categorized as clear (transparent or transparent with bluish tinge), nonclear (turbid), stable (no precipitation at the end of $24 \mathrm{~h}$ ), or unstable (showing precipitation within $24 \mathrm{~h}$ ).

\section{Characterization of SNEDDS}

\section{Droplet Size}

Using a Zetasizer 1000HS (Malvern Instruments, UK), the droplet size of (SNEDDS) was estimated using photon correlation spectroscopy, which analyses variations in light scattering owing to Brownian motion of the particle. Light scattering was monitored at $25^{\circ} \mathrm{C}$ at a $90^{\circ}$ angle. The optimized nanoemulsion sample was diluted by distilled water, placed in quartz corvette and subjected to droplet size analysis. ${ }^{4}$

\section{Zeta potential Analysis:}

Zetapotential of the optimum formulations was determined by dynamic light scattering using particle size analyser (Horiba scientific SZ-100, Horiba). The samples were diluted with a ratio of $1: 100(\mathrm{v} / \mathrm{v})$ with distilled water and repeated in triplicate. 5

\section{Viscosity measurement:}

The viscosity of SNEDDS was measured using small adapter of Brookfield cone and plate rheometer (Model LV2, Brookfield Engineering Laboratories, Stoughton, MA, USA) $12 \mathrm{rpm}$ at room temperature $\left(25 \pm 1^{\circ} \mathrm{C}\right)$, repeated in triplicate. ${ }^{6}$

\section{Thermodynamic stability studies:}

The optimum formula was subjected to further thermodynamic stability studies.

(1) Heating-Cooling cycle: Six cycles between $4^{\circ} \mathrm{c}$ and $45^{\circ} \mathrm{c}$ at each temperature for NLT 48hours were studied. The formulations that passed at this temperature without any signs of instability were subjected to centrifugation test.

(2) Centrifugation test: The formulations were centrifuged for 30 minutes at $3500 \mathrm{rpm}$. The formulations that did not show any signs of instability were chosen for the freeze-thaw cycle.

(3) Freeze-thaw cycle: The formulations were placed in temperature between $-21^{\circ} \mathrm{C}$ and $25^{\circ} \mathrm{C}$ with storage at each temperature for NLT 48 hours. Passed formulations were centrifuged 5 minutes at $3000 \mathrm{rpm}^{7}$

\section{The Morphology of SNEDDS:}

Transmission Electron Microscopy Joel JEM-100 CX was used to examine the SNEDDS morphology. The SNEDDS samples were diluted in water (1:1000), and a sample drop was stained for 30 seconds with a 2 percent phosphor tungstic acid solution and deposited on a copper grid. ${ }^{8}$

\section{RESULTS}

\section{SNEDDS preparation}

The compatibility of oil, surfactants, and co-surfactants to acquire a higher transmittance was the essential foundation in the fabrication of nano emulsion. The preliminary ratio was tested to determine the quantity of oil (olive oil) surfactant (Tween 80) co-surfactant (PEG 400) for further characterisation. The effect of surfactant ratio on transmittance is presented in the below table. The effect of surfactant ratio on transmittance. 
Table 2: Evaluation of SNEDDS Formulation

\begin{tabular}{|c|c|c|l|}
\hline Oil(ml) & Surfactant $(\mathrm{ml})$ & Co-surfactant(ml) & Transmittance (\%) \\
\hline 1 & 1 & 1 & $9.32 \pm 5.21$ \\
\hline 1 & 2 & 1 & $54.00 \pm 2.10$ \\
\hline 1 & 3 & 1 & $71.20 \pm 13.39$ \\
\hline 1 & 4 & 1 & $97.53 \pm 0.95$ \\
\hline 1 & 5 & 1 & $97.83 \pm 0.96$ \\
\hline 1 & 6 & 1 & $99.21 \pm 0.69$ \\
\hline 1 & 7 & 1 & $98.65 \pm 0.35$ \\
\hline
\end{tabular}

\section{Self-emulsification time:}

Visual assessment was used to examine the selfnanoemulsifying characteristics of SNEDDS formulations, as stated. These tests were done on a variety of SNEDDS formulations. During the study, it was found that some formulations, F1, F2 and F3 showed turbidity, precipitation and thus was not stable, due to the relative increase in surfactant concentration and the presence of PEG 400. Hence, F4, F5, F6 and F7 were prepared with increased concentrations of surfactant. Formulation F6 could be mixed Olive oil, Tween 80, and PEG 400 and hence was selected as good formulation and subjected to further investigation regarding droplet size, Zeta potential, etc. ${ }^{9}$

Evaluation of SNEDDS for droplet size analysis, zeta potential, and drug content determination

Droplet size distribution following self-nano emulsification is a critical factor to evaluate a self-nanoemulsion system. The mean globule size of selected SNEDDS formulation F7, of Raloxifene hydrochloride was $148.5 \mathrm{~nm}$ is indicated the ability of the present technology to produce nanoemulsion that offers larger interfacial surface area required for drug absorption. An increase in the ratio of the oily phase resulted in a proportional increase in particle size, because of the simultaneous Increase in the s/cos ratio led to decrease in mean droplet size.

The F6 SNEDDS showed high absolute zeta potential value of $-28.7 \mathrm{mv}$. The emulsion stability is directly related to the magnitude of the surface charge. Generally, an increase of electrostatic repulsive forces between nanoemulsion droplets prevents the coalescence of droplets. On the contrary, a decrease of electrostatic repulsive forces will cause phase separation. The results of zeta potential and drug content estimation are indicated in the given table. The percent drug content $99.21 \pm 0.69$ of SNEDDS of Raloxifene Hydrochloride was found satisfactory.

\section{Thermodynamic Stability:}

The best formulation was found to pass the thermodynamic stress tests. The optimum formulation showed no signs of instability, indicating that the system was stable. The SNEDDS system should create a nanoemulsion through spontaneous emulsification in the digestive tract. The SNEDDS system must have sufficient quality to withstand stability in order to restrain creaming, cracking, or precipitating. The selected formulation was subjected to heating-cooling cycle, centrifugation, and freeze thaw exposure. 10

Table 3: Evaluation of SNEDDS Formulation

\begin{tabular}{|l|l|l|l|}
\hline Stability test & Replication 1 & Replication 2 & Replication 3 \\
\hline Heating-cooling cycle & Pass & Pass & Pass \\
\hline Centrifugation & Pass & Pass & Pass \\
\hline Freeze-thaw cycle & Pass & Pass & Pass \\
\hline
\end{tabular}

\section{In vitro drug release study}

An in vitro release study was conducted for pure drug and SNEDDs of Raloxifene Hydrochloride in different dissolution media such as 2 percent sodium lauryl sulphate, simulated gastric fluid $(0.1 \mathrm{~N} \mathrm{HCl}$ containing 0.5 percent of Tween 20), and simulated intestinal fluid to better understand the characteristics of drug release from SNEDDs (pH 6.8 buffer). The dissolution profiles of pure drug and SNEDDS formulation are shown in Figure 2. As evident from the drug release profiles, the pure drug evidenced meagre solubility of $27.52 \%$ in $60 \mathrm{~min}$ in $2 \%$ SLS, $20.6 \%$ in $0.1 \mathrm{~N} \mathrm{HCl}$ containing $0.5 \%$ of Tween 20 and $20.93 \%$ in pH 6.8 buffer. The drug release from SNEDDS was markedly high such that $97.75 \%$ in $2 \%$ sodium lauryl sulphate, $95.73 \%$ in simulated gastric fluid $(0.1 \mathrm{~N} \mathrm{HCl}$ containing $0.5 \%$ of Tween 20 ) and $96.25 \%$ in simulated intestinal fluid ( $\mathrm{pH} 6.8$ buffer). The results indicate instantaneous and remarkably high dissolution of Raloxifene Hydrochloride in all three media compared to the pure drug. This higher and faster dissolution rate Raloxifene Hydrochloride from SNEDDS is expected due to the nanoparticle size range of the particles offering higher interfacial area required for dissolution.11,12

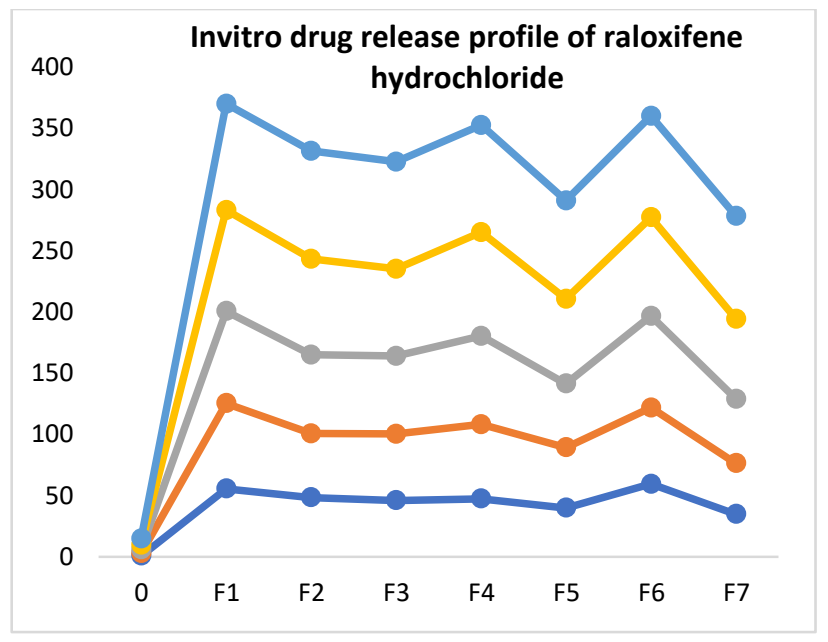

Figure 1: In-vitro drug release profile of raloxifene hydrochloride 
Table 4: Evaluation parameters of self-nanoemulsifying drug delivery systems formulation of Raloxifene-HCl, F6

\begin{tabular}{|l|c|}
\hline Evaluation Parameter & Results \\
\hline Mean Droplet size $(\mathrm{nm})$ & $148.5 \pm 2.350$ \\
\hline Mean Zeta Potential $(\mathrm{mv})$ & $-28.8 \pm 4.70$ \\
\hline$\%$ Drug Found $\left(\mathrm{mg} \mathrm{mL}^{-1}\right)$ & $99.69 \pm 6.1$ \\
\hline
\end{tabular}

\section{CONCLUSION:}

For oral administration, a SNEDDS containing Raloxifene hydrochloride was developed. Solubility studies, Pseudo ternary phase diagram creation, and droplet size analyses were used to determine the components and their ratio ranges for the formulation of SNEDDS. The ideal SNEDDS formulation featured adequate drug loading, quick self nano emulsification in aqueous media, and droplet sizes in the nano emulsion range.

\section{REFERENCES:}

1. Jeevana JB, Sreelakshmi K. Design and evaluation of selfnanoemulsifying drug delivery system of flutamide. J Young Pharm. 2011; 3(1):4-8. https://doi.org/10.4103/09751483.76413

2. Elsheikh MA, Elnaggar YSR, Gohar EY, Abdallah OY. Nanoemulsion liquid preconcentrates for raloxifene hydrochloride: Optimization and in vivo appraisal. Int J Nanomedicine. 2012; 7: 3787-802. https://doi.org/10.2147/IJN.S33186

3. Patel J, Patel A, Raval M, Sheth N. Formulation and development of a self-nanoemulsifying drug delivery system of irbesartan. J Adv Pharm Technol Res. 2011; 2(1):9-16. https://doi.org/10.4103/2231-4040.79799

4. Balakumar K, Raghavan CV, selvan NT, prasad RH, Abdu S. Self nanoemulsifying drug delivery system (SNEDDS) of Rosuvastatin calcium: Design, formulation, bioavailability and pharmacokinetic evaluation. Colloids Surfaces B Biointerfaces
[Internet]. 2013; 112:337-43.

https://doi.org/10.1016/j.colsurfb.2013.08.025

5. Sakulku U, Nuchuchua O, Uawongyart N, Puttipipatkhachorn S, Soottitantawat A, Ruktanonchai U. Characterization and mosquito repellent activity of citronella oil nanoemulsion. Int J Pharm. 2009; 372(1-2):105-11.

https://doi.org/10.1016/j.ijpharm.2008.12.029

6. Shafiq S, Shakeel F, Talegaonkar S, Ahmad FJ, Khar RK, Ali M. Development and bioavailability assessment of ramipril nanoemulsion formulation. Eur J Pharm Biopharm. 2007; 66(2):227-43. https://doi.org/10.1016/j.ejpb.2006.10.014

7. Zhao Y, Wang C, Chow AHL, Ren K, Gong T, Zhang Z, et al. Selfnanoemulsifying drug delivery system (SNEDDS) for oral delivery of Zedoary essential oil: Formulation and bioavailability studies. Int J Pharm. 2010; 383(1-2):170-7. https://doi.org/10.1016/j.ijpharm.2009.08.035

8. Bandyopadhyay S, Katare OP, Singh B. Optimized self nanoemulsifying systems of ezetimibe with enhanced bioavailability potential using long chain and medium chain triglycerides. Colloids Surfaces B Biointerfaces [Internet]. 2012; 100:50-61. https://doi.org/10.1016/j.colsurfb.2012.05.019

9. Tanya M. Smedds/Snedds: an Emerging Technique To Solubility Enhancement for the Pharmaceutical Industry. World J Pharm Pharm Sci. 2017; 6(7):317-36. https://doi.org/10.20959/wjpps20177-9493

10. Gupta P, Sharma PK, Kumar N, Pawar Y, Gupta J. Self nano emulsifying drug delivery system: a strategy to improve oral bioavailability. World J Pharm Pharm Sci [Internet]. 2014; 3(5):506-12, 7 pp. Available from: http://www.wjpps.com/admin/assets/article_issue/13990163 90.pdf

11. Dash Tapaswi Rani, Sharma Pankaj, Sharma Sawati SP. Novel self-nanoemulsifying drug delivery systems (SNEDDS) for oral delivery of lipophilic drugs. Indo Am J Pharm Res. 2017; $7(1): 7361-8$.

12. Savale SK. a Review - Self Nanoemulsifying Drug Delivery System (Snedds). Int J Res Pharm Nano Sci [Internet]. 2015; 4(6):38597. Available from: http://www.ijrpns.com/article/A review self nanoemulsifying drug delivery system (SNEDDS).pdf 